\title{
A APLICAÇÃO DA NBR ISO 20121 NA GESTÃO DA SUSTENTABILIDADE EM EVENTOS: O FORTALECIMENTO DA MARCA POR MEIO DA PRODUÇÃO DE EVENTOS MAIS SUSTENTÁVEIS EM SANTA CATARINA
}

\author{
Ení Maria Ranzan ${ }^{1}$ \\ Andreia Luzia Mauricio \\ Richard Perassi Luiz de Sousa ${ }^{3}$
}

\section{INTRODUÇÃO}

O crescimento do mercado brasileiro de eventos está alavancando o turismo de negócios, por meio da realização de eventos nacionais e da captação de eventos internacionais. A realização destes eventos, independentemente de seu porte, necessita da elaboração de muitos produtos e serviços para sua viabilidade. Neste processo estão envolvidos não somente atores da comunidade que sediará o evento, bem como de outras regiões quando a mão de obra e/ou os serviços locais não tenham a qualificação necessária para este fim (GIACAGLIA, 2006; ALLEN et. al, 2003). Nas ações pertinentes a viabilização dos serviços, previstas especialmente na fase do planejamento do evento, faz-se necessário observar princípios para que os eventos possam ser realizados da maneira mais sustentável. Os benefícios gerados pelos eventos aos atores envolvidos estão acompanhados por aspectos negativos, que impactam nas dimensões ambiental, social, econômica, cultural e política. Estas preocupações pautaram a criação da norma NBR ISO 20121, que orienta sobre a gestão da sustentabilidade em eventos.

Contemplando a educação ambiental para a sustentabilidade, pretendeu-se verificar a aplicação dos princípios da sustentabilidade no planejamento e execução de eventos, pelos organizadores de eventos catarinenses. Desta forma esta é uma pesquisa integrativa e exploratória, realizada por meio de pesquisa de campo. Buscou-se entrevistar os gestores das empresas (cadastradas junto a $A B E O C$ ), para identificar sua percepção sobre sustentabilidade, bem como as ações que usualmente são realizadas pelos mesmos para a realização de eventos mais sustentáveis.

Apresenta-se, na sequência: a fundamentação teórica que embasa este trabalho; a descrição dos procedimentos metodológicos; os principais resultados alcançados; e as considerações finais percebidas.

\footnotetext{
1 Doutoranda PPG-EGC - Universidade Federal de Santa Catarina - enimariaufsc@gmail.com

${ }^{2}$ Técnica em Eventos - IFSC Florianópolis Continente - andreia-mauricio@hotmail.com

${ }^{3}$ Professor PPG-EGC - Universidade Federal de Santa Catarina - richard.perassi@uol.com.br
} 


\section{A GESTÃO DE EVENTOS MAIS SUSTENTÁVEIS}

A ideia de sustentabilidade, surgida nas décadas de 60 e 70, tem estado cada vez mais presente em nosso cotidiano. $O$ conceito de sustentabilidade (neste estudo) considera como ponto de partida o Relatório Nosso Futuro Comum ${ }^{4}$ que defende o desenvolvimento sustentável como sendo "aquele que atende às necessidades do presente sem comprometer a capacidade de as gerações futuras atenderem também às suas" (FONTES et.al, 2008, p. 13). Não se pretende uma sociedade estagnada. Buscam-se, porém, caminhos alternativos para o limite de crescimento numa relação mais harmoniosa com a natureza.

As dimensões da sustentabilidade, conforme a filosofia e as práticas do Triple Botton Line - $\mathrm{TBL}^{5}$ (também conhecido como o tripé da sustentabilidade) remetem para um desempenho integrado nas abordagens ambientais, sociais e econômicas (MATTIODA \& CANCICLIERI, 2012). Este conceito defende que as três dimensões devem interagir de maneira holística na busca ações organizacionais sustentáveis.

As dimensões TBL podem estar presentes na organização de eventos, priorizando ações que considerem o equilíbrio ecológico, o desenvolvimento econômico e a igualdade de oportunidades para a sociedade. Indo além destes aspectos, é possível acrescentar as dimensões culturais e políticas na organização de eventos. É necessário aliar ao planejamento e execução do evento ações pontuais que, articuladas entre si, respeitem as cinco dimensões. A organização de eventos mais sustentáveis (ou eventos verdes) é possível, desde que estas dimensões sejam seguidas. Algumas destas ações podem ser conferidas no quadro 1.

A organização de eventos mais sustentáveis (ou eventos verdes) é possível, desde que estas dimensões sejam seguidas.

Quadro 1: Caminhos possíveis para a prática da sustentabilidade em eventos

\footnotetext{
${ }^{4}$ Elaborado pela Comissão Mundial sobre o Meio Ambiente e Desenvolvimento, da ONU, em 1987.

${ }^{5}$ Ferramenta criada na década de 90 pelo sociólogo e consultor britânico John Elkington, que mede os cuidados com as pessoas (people) e o capital natural (planet), aliado ao resultado econômico (profit).
} 


\begin{tabular}{|c|c|}
\hline Princípios & Ações sugeridas \\
\hline $\begin{array}{l}\text { Uso de recursos } \\
\text { naturais } \\
\text { de forma responsável }\end{array}$ & $\begin{array}{l}\text { Reduzir o consumo de energia, água, bens e serviços; } \\
\text { Reduzir a geração de resíduos; } \\
\text { Priorizar o uso de objetos duráveis ao invés dos descartáveis; } \\
\text { Buscar a máxima reutilização de materiais; } \\
\text { Priorizar o uso de recursos naturais renováveis; } \\
\text { Priorizar o uso de materiais recicláveis e reciclados; } \\
\text { Optar por alimentos orgânicos; } \\
\text { Encaminhar resíduos para reciclagem e compostagem; } \\
\text { Otimizar o transporte coletivo e solidário; } \\
\text { Valorizar iluminação e ventilação naturais. }\end{array}$ \\
\hline $\begin{array}{l}\text { Oportunizar } \\
\text { desenvolvimento } \\
\text { econômico mais justo }\end{array}$ & $\begin{array}{l}\text { Priorizar a oportunidade de negócios para empreendimentos econômicos populares e } \\
\text { solidários (cooperativas, associações e microempresas); } \\
\text { Negociar preços justos. }\end{array}$ \\
\hline $\begin{array}{l}\text { Favorecer o acesso } \\
\text { de forma democrática }\end{array}$ & $\begin{array}{l}\text { Escolher um lugar para o evento que seja de fácil acesso, receptivo a diferentes; } \\
\text { pessoas, de diferentes níveis socioculturais; } \\
\text { Adequar o espaço físico para pessoas com necessidades especiais de locomoção; } \\
\text { Divulgar o evento em diferentes mídias, e setores urbanos, para levar a informação a } \\
\text { pessoas interessadas de diferentes níveis socioculturais; } \\
\text { Praticar preços justos ara inscrição no evento. }\end{array}$ \\
\hline $\begin{array}{l}\text { Valorizar saberes } \\
\text { práticos e populares }\end{array}$ & $\begin{array}{l}\text { Prever atividades para vivência e experimentação; Realizar excursões e estudos de } \\
\text { campo; Criar momentos culturais para apreciação do saber popular. }\end{array}$ \\
\hline $\begin{array}{l}\text { Fomentar a unidade, } \\
\text { sentido de pertença e } \\
\text { coletividade }\end{array}$ & $\begin{array}{l}\text { Favorecer espaços de encontro; Evitar as atividades paralelas e o isolamento de } \\
\text { grupos; Oportunizar encontros entre diferentes comunidades; } \\
\text { Ampliar o contato dos participantes com várias formas de representação cultural, local } \\
\text { e regional (artesanato, música, dança, cinema, culinária...); } \\
\text { Respeitar as necessidades e ritmos humanos na programação de atividades; } \\
\text { Respeitar sensibilidades e necessidades da comunidade do entorno. }\end{array}$ \\
\hline $\begin{array}{l}\text { Valorizar as escalas } \\
\text { regionais e locais }\end{array}$ & $\begin{array}{l}\text { Trabalhar as escalas na escolha de roteiros de excursão, atividades artísticas, produtos } \\
\text { oferecidos e serviços prestados, dimensionamento e logística do evento, favorecendo a } \\
\text { integração e proximidade de diferentes pessoas. }\end{array}$ \\
\hline $\begin{array}{l}\text { Promover a } \\
\text { participação } \\
\text { ativa e cidadã }\end{array}$ & $\begin{array}{l}\text { Construir processos transparentes de gestão do evento; } \\
\text { Compartilhar informações de maneira clara e permanente; } \\
\text { Partilhar as tomadas de decisões (no planejamento e execução do evento); } \\
\text { Formar equipes de trabalho autogestionárias e motivadas pela cooperação; } \\
\text { Esclarecer e definir em conjunto as atribuições de cada um no trabalho em equipe; } \\
\text { Capacitar pessoas interessadas em participar. }\end{array}$ \\
\hline $\begin{array}{l}\text { Fortalecer parcerias e } \\
\text { instituições }\end{array}$ & $\begin{array}{l}\text { Buscar parcerias com instituições que compartilham os princípios da sustentabilidade } \\
\text { e multiplicam experiências neste âmbito. }\end{array}$ \\
\hline
\end{tabular}

Fonte: Ranzan e Perassi (2015), elaborado a partir de Fontes et. Al.

As ações sugeridas podem ser ampliadas e adaptadas conforme as características de cada evento (tipo, porte, abrangência, etc.), podendo utilizadas parcialmente ou na sua totalidade. A dimensão ambiental está presente nas ações que buscam utilizar os recursos naturais de forma responsável. As ações que oportunizam um desenvolvimento econômico mais justo contemplam a dimensão 
econômica. A social favorece o acesso de forma democrática, entre outras articuladas com as demais dimensões. A valorização dos saberes práticos e populares remete para a dimensão cultural, mas reporta-se também à dimensão social. A valorização das escalas regionais e locais remete para a dimensão política, mas está imbricada nas dimensões culturais e sociais igualmente. Também estão integradas nestas dimensões, com ênfase na dimensão política, ações relacionadas ao fomento da unidade, do sentido de pertença e coletividade, bem como a participação ativa e cidadã e o fortalecimento de parcerias e instituições. O universo de ações que podem ser inseridas neste contexto, para a produção de eventos mais sustentáveis, não se esgota com as ações propostas no quadro. Ele pode ser um ponto de partida para os gestores que pretendem iniciar pelo caminho da sustentabilidade na organização de seus eventos.

Estas e outras soluções para a implementação de um sistema de gestão na organização de eventos mais sustentáveis estão propostas na norma NBR ISO $20121^{6}$. Esta norma sugere ações a serem adotadas, porém sua aplicação é opcional. Não há obrigatoriedade de sua implantação parcial ou total na implementação dos eventos. Ela fornece um framework que orienta os gestores ao planejar um evento, possibilitando corrigir os impactos negativos e a potencialização de ações positivas, tendo como base as dimensões da sustentabilidade.

O ciclo de gestão de eventos, previsto na Norma, entende todas as fases de um evento, desde concepção, planejamento, execução e pós-evento. $O$ desenvolvimento sustentável deve considerar tanto a cadeia produtiva e o engajamento com as partes interessadas, como as necessidades dos usuários finais. O sucesso da implementação da ISO 20121 deve considerar o total comprometimento da alta direção, abrangendo todos os stakeholders envolvidos neste processo.

A adoção de medidas que reduzem os impactos ambientais e a sensibilização das pessoas envolvidas, em relação à sustentabilidade, trazem efeitos positivos, que melhoram "a imagem do evento em face de seu público participante" (SANTOS, 2011, p. 190). Esta imagem favorável do evento (e consequentemente dos organizadores) reflete sobre todos os stakeholders

\footnotetext{
${ }^{6}$ Criada pela British Standards Institute-BSI (Inglaterra) e Associação Brasileira de Normas Técnicas -ABNT (Brasil), tendo como base a organização das Olimpíadas de Londres em 2012.
} 
envolvidos. Estes ao transmitirem valores positivos "levam as pessoas a acreditarem em sua marca e em seus produtos e serviços". (CHAVES, 2012, p.6). A escolha por ações que salvarão o planeta será associada ao nome do evento ou da organização (SANTOS, 2011), transformando-se num diferencial. O conceito da organizadora de eventos e/ou de um evento mais sustentável estará expresso naquela marca associada a sustentabilidade.

\section{PROCEDIMENTOS METODOLÓGICOS}

Esta investigação tem caráter exploratório e descritivo, realizada por meio de pesquisa bibliográfica integrativa, do estudo da norma NBR ISO 20121 e de pesquisa de campo. Os termos pesquisados foram gestão de eventos e sustentabilidade em eventos. Igualmente buscaram-se publicações de instituições da área de eventos, como: ICCA, ABEOC, Ministério do Turismo, OMT, entre outras, para trazer a percepção do mercado atual. A pesquisa de campo foi realizada por meio do estudo de caso junto as empresas organizadoras de eventos, cadastradas junto a ABEOC/SC. Foi encaminhado mensagem as 52 empresas, explicando sobre a pesquisa e convidando-as para participar. Agendou-se entrevista semiestruturada com as 20 primeiras empresas que retornaram aceitando o convite. As entrevistas foram gravadas e os não foram divulgados os nomes das empresas e entrevistados, atribuindo-se letras aleatórias aos mesmos para manter o anonimato dos gestores entrevistados. Optou-se por não mencionar, durante o processo, a existência da norma NBR ISO 20121, para não influenciar nas informações prestadas pelos entrevistados. Desta forma foi possível perceber os princípios seguidos pelas organizações, independente das orientações da norma. Destacou-se, durante a entrevistas, aspectos como: concepção de eventos sustentáveis, aspectos sociais, ambientais e econômicos praticados no planejamento e organização dos eventos, valorização da cultura local e uso de tecnologias, registros das ações realizadas, conhecimento de norma alusiva a gestão da sustentabilidade em eventos, entre outros

\section{PRINCIPAIS RESULTADOS OBTIDOS}


Desta forma contextualizou-se, inicialmente, o desenvolvimento sustentável e seus princípios. Na sequência o olhar voltou-se para a realização de eventos mais sustentáveis, buscando-se a convergência entre os eventos e a sustentabilidade, incluindo-se a contextualização da norma NBR ISO 20121. Os resultados são apresentados a partir das discussões pontuadas no roteiro das entrevistas. Os gestores não partem de um conceito padrão ao contextualizar a sustentabilidade. Em relação as ações mais sustentáveis estes fazem o que julgam "ser correto". Os pilares base da sustentabilidade são o ambiental, o político, o econômico, o social e o cultural, porem 64\% dos entrevistados destacam ter preocupações com ações pertinentes ao ambiental, 15\% com o cultural e 10\% com o econômico. Os aspectos políticos (6\%) e social (5\%) foram pouco mencionados. Complementando estas informações, 65\% destacam que a sustentabilidade está focada na redução de resíduos e na ecologia (6\%); 15\% relacionam a sustentabilidade com questões financeiras (viabilidade) e 10\% mencionam que a sustentabilidade remete para credibilidade. Os gestores indicaram que suas equipes de trabalho estão mais focadas com a execução das atividades alusivas, do que com as ações de sustentabilidade (durante a realização dos eventos). No entanto cuidados com a destinação do lixo, o uso de papel reciclado, a redução de uso de plásticos e reaproveitamento de materiais são escolhas constantes no planejamento e execução de eventos. Detalhando estas questões, houveram outros destaques importantes: a maior parte das empresas faz separação de resíduos dentro da empresa, mas nem sempre conseguem aplicar este cuidado na realização de seus eventos (depende do local e de quem contrata os serviços). Quando o evento é de responsabilidade total da organizadora é possível controlar mais as escolhas e fazer as ações sustentáveis que gostariam de fazer. A comunidade local é beneficiada com a realização dos eventos (na percepção de 75\% dos entrevistados) por meio de parcerias com restaurantes, hotéis, bares, entre outros. Outro benefício destacado pelos gestores é o aumento do fluxo de visitação que beneficia lojas, mercados, shoppings e o comércio local de maneira geral. Os eventos de maior porte chegam a utilizar os equipamentos de cidades próximas para atender a demanda, indo além do benefício à comunidade local. Igualmente houve destaque para a geração de empregos temporários para atender as necessidades de cada evento. Em relação a valorização da cultura e gastronomia local é feita sempre que o contratante permite, o que possibilita mostrar um pouco da diversidade catarinense. As empresas 
organizadoras de eventos procuram utilizar a tecnologia a seu favor. Os principais destaques referem-se à diminuição de impressões, como: o uso de mídia eletrônica e redes sociais para divulgação dos eventos e o uso de projeções para substituir painéis e banners. Em relação a documentação dos processos nas fases de planejamento e execução de eventos, os gestores elaboram os projetos dos respectivos eventos, bem como controles financeiros e de materiais. Poucos elaboram documentos e/ou os Poucos gestores tinham conhecimento da norma NBR ISO 20121.

\section{CONSIDERAÇÕES FINAIS}

Este estudo contemplou o estudo ambiental para a sustentabilidade. Seu objetivo de verificar a aplicação dos princípios da sustentabilidade em eventos, pelos organizadores de eventos catarinenses foi atendido durante o processo. Foi possível perceber que, apesar dos gestores terem entendimentos diferentes sobre sustentabilidade, todos adotam ações pertinentes durante os processos de planejamento e execução de eventos.

As empresas catarinenses mostraram-se abertas para o desafio de organizarem eventos mais sustentáveis, apesar do pouco conhecimento de alguns ou das dificuldades diversas apresentadas por outros. Esta iniciativa (em maior ou menor medida) é intrínseca a percepção e crença do gestor da organização, pois este mercado carece de uma formação mais precisa neste sentido. A norma é pouco conhecida e foi pouco citada como uma possível orientação para a gestão do processo de organização de eventos.

As principais vantagens destacadas pelos entrevistados, na produção de eventos mais sustentáveis, está relacionada com: Incorporação da sustentabilidade à identidade do evento; redução de custos operacionais com menos desperdício e melhor utilização dos materiais; melhora da imagem da organizadora e do evento junto a sociedade; redução de emissão de gás do efeito estufa; o evento deixa um legado positivo para a comunidade receptora; o controle da gestão remete para uma 'sustentabilidade verdadeira'; e a realização de eventos mais sustentáveis fortalece a construção da marca de um evento. Percebeu-se que a dimensão ambiental está mais presente na mente dos gestores ao defenderem a sustentabilidade nos 
eventos, porem as dimensões social, econômica, cultural e política está presente em seus depoimentos, mesmo sem destacar tratar-se de ações de sustentabilidade.

O uso da norma NBR ISO 20121 apresenta-se como uma alternativa para a tomada de decisões, orientando os gestores e a cadeia produtiva, envolvidos na promoção dos eventos. A possibilidade da implementação parcial ou globalmente deixa os gestores mais à vontade para adotarem a mesma em seus negócios. Naturalmente faz-se necessário maior disseminação da Norma, porem percebe-se que os gestores já estão sensibilizados pela possibilidade de realizarem eventos mais sustentáveis.

A pesquisa proposta não se esgota neste momento. Esta faz parte de um estudo maior sobre a gestão de eventos mais sustentáveis, que resultará na realização de uma tese de doutorado. Desta forma muitos desdobramentos serão possíveis, vislumbrando-se a possibilidade de contribuir com os stakeholders do mercado de eventos, mas especialmente com a comunidade científica sobre a temática eventos mais sustentáveis.

\section{REFERÊNCIAS}

ABNT NBR ISO 20121. Sistemas de gestão para sustentabilidade de eventos Requisitos com orientações de uso. 2012.

ALLEN, Johnny; O'TOOLE, William; McDONNEL, Ian; HARRIS, Roberto.

Organização e gestão de eventos. Rio de Janeiro: Elsevier, 2003.

Chaves, Natália Cristina Alves Caetano. Marca, Imagem, Discurso e Cultura Organizacional. In: Comunicon, 2012. São Paulo. Anais do Comunicon 2012. Disponível em:

<http://www.espm.br/download/Anais_Comunicon_2012/comunicon/gts/gtdez/NATA LIACRISTINAALVESCAETANOCHAV̄ES.pdf>. Acesso em: 08 maio 2015.

FONTES, Nádia; ZANIN, Maria; TEIXEIRA, Bernardo Arantes do Nascimento; YUBA, Andrea Naguissa; SHIMBO, Ioshiaqui; INO, Akemi; LEME, Patrícia Cristina Silva. Eventos mais sustentáveis: uma abordagem ecológica, econômica, social, cultural e política. São Carlos: EdUFSCar, 2008. 
GIACAGLIA, Maria Cecília. Organização de Eventos: Teoria e prática. São Paulo: Pioneira Thomson, 2006.

MATTIODA, Rosana; CANCICLIERI JR., Osiris. Abordagem dos conceitos do triple bottom line no desenvolvimento integrado de produtos. Revista Sodebras, v. 7, 2012. Disponível em:

$<$ https://www.researchgate.net/publication/281243882_ABORDAGEM_DOS_CONC EITOS_DO_TRIPLE_BOTTOM_LINE_NO_DESENVOLVIMENTO_INTEGRADDO_DE _PRODUTŌS_->. Acesso em $1 \overline{8}$ abr. 2016.

PICCIN, Ana Carolina; DOWELL, Daniella Mac. Eventos mais sustentáveis. In: MATIAS, Marlene (org.). Planejamento, organização e sustentabilidade em eventos: culturais, sociais e esportivos. Barueri: Manole, 2011.

RANZAN, Ení Maria; PERASSI, Richard. Princípios normativos aplicados ao processo de gestão e consolidação da marca de sustentabilidade em eventos. In.: Congresso Internacional de Conhecimento e Inovação, 5., 2015, Joinville. Anais do $5^{\circ}$ Congresso Internacional de Conhecimento e Inovação. v.4, Florianópolis: UFSC Editora, 2015. p. 2162-2181.

SANTOS, Meire Dias dos. Eventos verdes. In: MATIAS, Marlene (org.). Planejamento, organização e sustentabilidade em eventos: culturais, sociais e esportivos. Barueri: Manole, 2011. 